\title{
Power Moderates the Effects of Social Dominance Orientation on Punishment: An Experimental Analysis
}

Psychological Reports

$0(0) 1-18$

(C) The Author(s) 2018

Reprints and permissions: sagepub.com/journalsPermissions.nav DOI: I0.II77/0033294| I8755095 journals.sagepub.com/home/prx

@SAGE

\section{Maria Sophia Heering \\ School of Psychology, University of Kent, UK}

\section{Luigi Leone}

Department of Social and Developmental Psychology, "Sapienza" University of Rome, Rome, Italy

\begin{abstract}
In this study, it was hypothesized that experimentally manipulated levels of power would moderate the association of dispositional social dominance orientation (SDO) with preferences for harsh punishment. In particular, we expected to detect a stronger effect for dispositional SDO in the low-power condition, relying on the notion that low power enhances sensitivity to threats to the status quo, and that high SDO individuals are particularly motivated to enforce hierarchy-enhancing measures as punishment. SDO scores were measured two months prior to the experiment, and then immediately after the experimental session. As expected, preexperimental SDO interacted with the power manipulation. We found stronger preexperimental SDO effects on punishment among low-power participants. We also anticipated and found that individuals high in SDO increased further their postexperimental SDO scores if assigned to a high-power condition. The discussion focuses on the importance of SDO effects among low-status groups and on how situational roles shape dispositional self-descriptions.
\end{abstract}

\section{Keywords}

Social dominance orientation, social dominance theory, power, punishment, moderation

\section{Corresponding Author:}

Luigi Leone, Department of Social and Developmental Psychology, "Sapienza" University of Rome,

Rome, Italy.

Email: luigi.leone@uniromal.it 


\section{Introduction}

Punishment has been a topic widely discussed in psychology and is relevant for research and theory in several areas (e.g., Carlsmith, Darley, \& Robinson, 2002; Gollwitzer \& Keller, 2010; Podsakoff, Bommer, Podsakoff, \& MacKenzie, 2006; Wenzel \& Okimoto, 2016). The importance of punishment for individuals and human groups can be traced back to an evolutionary account that emphasizes how groups (as hunter-gatherer societies) needed to install punishment mechanisms to check free-riders and, as well, to deter disloyal behaviors that put the social order at risk (Gollwitzer \& van Prooijen, 2016). Such accounts are consistent with the definition of punishment as a device used to reduce the probability of undesired behaviors. This definition, in turn, straightforwardly explains why punishment dynamics is a key topic in organizational (e.g., Podsakoff et al., 2006), justice-related (e.g., Carlsmith et al., 2002; Okimoto \& Wenzel, 2008), and criminal and legal psychology research (e.g., Kemmelmeier, 2005; Sidanius, Liu, Shaw, \& Pratto, 1994).

Organizational studies have tackled the dynamics of punishment from the perspective of organizational efficiency, the role of management effectiveness in administering rewards and punishments, and the dynamics of manager-employee relationships and perceptions (Podsakoff et al., 2006). Research on justice has investigated the roles of moral emotions and other motives (retribution vs. utilitarianism or retribution vs. restoration) in determining punishment (e.g., Carlsmith \& Darley, 2008; Wenzel \& Okimoto, 2016). It should be noted that both organizational and justice-related research on punishment share a favorable functional evaluation of punishment systems. They can be interpreted as social devices selected by evolutionary processes with predominantly positive consequences for the functioning of groups (Balliet, Mulder, \& Van Lange, 2011; Gollwitzer \& Van Prooijen, 2016). As a point of difference, legal and judicial psychology research has somewhat emphasized the biases linked with how and on whom punishment systems operate, thus considering a darker side of punishment within and between social groups (e.g., Carlsmith \& Sood, 2009; Sidanius \& Pratto, 1999). For instance, a large body of research has focused on grouplevel variables as ethnicity and status to account for biases in the degree of recommended punishment. This literature in general emphasizes a proclivity to administer harsher punishment to members of ethnic minorities with lower status and, in general, to lower status out-groups (e.g., Gross \& Mauro, 1989). This notwithstanding, biases in the opposite direction (disfavoring the in-group member for the out-group member) also have been identified. In research on the so-called black sheep effect, it has been found that in-group offenders are punished more harshly than out-group offenders (e.g., Gollwitzer \& Keller, 2010). Such an effect appears to be asymmetrical across high- and low-power groups: In low-power groups, individuals seem to punish more harshly in-group members, as compared with high-power groups (e.g., Sidanius \& Pratto, 1999). However, 
such group-level effects on punishment appear highly variable. For instance, it has been shown that the black sheep effect could be reversed under some circumstances (e.g., Van Prooijen, 2006). As well, after contradictory results on the issue of ethnic bias in judicial decisions accumulated over the years, it appeared that no unqualified systematic association between ethnicity- and status-related factors and harsh punishment could be found (Mazzella \& Feingold, 1994).

Such difficulties in detecting consistent group-level effects on preferences for harsh punishment have provided motivation to look for individual-level variables that could explain preferences for harsh punishment. On this score, social dominance orientation (SDO; Pratto, Sidanius, Stallwarth, \& Malle, 1994) has been consistently identified as an individual-level correlate of preferences for harsh punishment (e.g., Sidanius et al., 1994; Capps, 2002). Perhaps more interestingly, SDO has been shown to interact with group-level variables in shaping punishment and derogation (Kemmelmeier, 2005; Levin, Sidanius, Rabinowitz, \& Federico, 1998; Sidanius, Pratto, van Laar, \& Levin, 2004). For instance, social dominance has helped to better understand the null effects of ethnicity frequently found in mock jury research, showing that when the defendant was white, higher SDO predicted less severe sentences but this relationship was reversed when the defendant was black (Kemmelmeier, 2005). Failing to consider the interaction with individual-level SDO could wrongly suggest that differences in status and ethnicity would have simply no effect on punishment preferences.

Thus, SDO has been interpreted as an individual-level variable interacting with group-level variables in shaping preferences for harsh punishment and other determinations (Levin et al., 1998; Sidanius et al., 2004). In a similar vein, we would argue that the effects of SDO on preferences for harsh punishment would not be constant across a key group-level variable, i.e., levels of power. Punishment has been related in various and complex ways to varying levels of power (Fiddick \& Cummins, 2007; Van Prooijen \& Lam, 2007). It appears therefore important to study the possible interaction of levels of power, as a manipulated group-level variable, and SDO as an individual-level variable in shaping preferences for harsh punishment. We would anticipate that the effects of SDO on preferences for harsher punishment would be stronger when individuals are placed in lowpower contingencies, while the effects of SDO would become weaker when individuals are placed in high-power contingencies. Before turning to a more detailed description of the rationale sustaining such expectations, we will first briefly review the associations of SDO and levels of power with preferences for punishment.

\section{Levels of power and punishment}

Following Keltner, Gruenfeld, and Anderson (2003), we adhere to a definition of power as an 'individual's relative capacity to modify others' states by providing or withholding resources or administering punishment" (p. 265). As can be noted, the definition of power we adopt has at its core the ability to administer 
punishment. From this definition, it also follows that those in power would be more frequently demanded by the circumstances and by their roles to administer punishment to modify others' states and behaviors, as it is the case in organizations, political and policy settings, and the like. However, the fact that the powerful have means and opportunities to administer punishment does not necessarily imply that wielding power per se entails preferences for harsher forms of punishment. On the contrary, research has identified various factors that could lead those low in power to resort to punishment. Consider, for instance, situations where deviance represents a threat, and punishment may be imposed as a way of dealing with that threat. Because it has been shown that perceptions of personal threat occur more frequently in low-status groups (Keltner et al., 2003; Scheepers \& Ellemers, 2005), it could be fairly easily argued that in the eyes of lower status individuals, compared with higher status individuals, the threatening transgressors could appear more menacing and dangerous. Given that threat's prime motivations to punish (e.g., Wenzel \& Okimoto, 2016), it is conceivable that disempowered groups may feel a strong desire, underpinned by fear and perceptions of danger, for harsher retribution (e.g., Okimoto \& Wenzel, 2008). Instead, compared with low-power individuals, powerful individuals can afford to be relatively unconcerned about deviants or free-riders because their powerful position can make many forms of mild deviance unthreatening, particularly when the free-rider or transgressor belongs to a low-power category (Van Prooijen \& Lam, 2007). The resilience of high-power individuals to the social threat embodied by deviants and transgressors has been found to endure in their tolerant attitude toward free-riders, as indicated in a few studies. Van Prooijen and Lam (2007) found that high status leads to milder punishment of out-group members compared with low status, and Fiddick and Cummins (2007) found that high-power individuals were less punitive toward transgressors. Such preference for leniency could be interpreted as a preference by high-power individuals or groups to conform to norms of magnanimity toward subordinates, the so-called "noblesse oblige" norm, which inhibits high-power groups or individuals from resorting to harsher - even though legitimate - forms of punishment (Fiddick, Cummins, Janicki, \& Erlich, 2013).

To summarize, research on power and relative-group power appears to indicate that, in general, differing levels of power impact on preferences for harsh versus lenient forms of punishment (Fiddick et al., 2013). More specifically, research on this issue does not appear to point to the simple conclusion that high power motivates harsher punishment. Rather, the contrary seems to be the case: Low-power groups appear more motivated to punish deviance instead (Scheepers, Branscombe, Spears, \& Doosje, 2002; Van Prooijen \& Lam, 2007; Wenzel \& Okimoto, 2016). However, it must be noted that the notion of a simple stronger preference for harsher punishment by low-power groups or individuals does not provide a reliable picture of the complex effects on punishment of power and status, because these effects could take opposite directions 
(Kafashan, Sparks, Griskevicius, \& Barclay, 2014). Besides, inferring a generalized tolerance and leniency toward transgressors by high-power individuals does not readily fit with well-established theoretical models, such as the influential social dominance theory, that emphasize instead the systematic use of punishment and other forms of control by the powerful to maintain the hierarchical status quo (e.g., Sidanius \& Pratto, 1999). Finally, focusing only on the main effects of power on punishment ignores the importance of variation across individuals in their preference for hierarchy-enhancing attitudes and behaviors as key in shaping reactions to deviance (e.g., Sidanius et al., 2004).

\section{Social dominance and punishment}

SDO, defined as the individuals' preference for inequality and hierarchy among social groups and individuals, has been associated with preference for harsher punishment and more frequent reliance on punishment to deal with transgressions (e.g., Pratto et al., 1994). Individuals high in SDO are motivated to punish to enforce norms that sustain a hierarchical status quo and defend their status position from challenging threats. Consistent with such reasoning, associations between higher levels of SDO with both punitiveness scores and support for harsher forms of punishment have been found (e.g., Capps, 2002). A straightforward (main effect or zero-order) correlation between individual differences in SDO and preferences for harsher punishment for transgressors who are perceived to be competitive and, hence, a potential threat to the established hierarchical arrangement (Cohrs \& Asbrock, 2009) is thoroughly consistent with the SDO definition. It is also consistent with the wider social dominance theory, which includes SDO as an individual difference variable (Sidanius \& Pratto, 1999). Notwithstanding such reliable zero-order (main effects) associations between SDO and preferences for harsher punishment, it should be emphasized that social dominance theory (e.g., Sidanius \& Pratto, 1999) allows for more complex patterns of associations that conceptualize SDO effects as contingent on situational, institutional, and group-level phenomena (Sidanius et al., 2004). Otherwise put, the social context may moderate the influences of SDO.

\section{The case for interactions between SDO and levels of power}

Pratto et al. (1994) specified that social dominance effects are not bound to occur only in the guise of simple or main effects. Rather, "social dominance theory implies that SDO and other individual variables must be considered within their social context" (p. 757). Power is one important feature of a wide array of social contexts. SDO, which captures also the individual's attentiveness to the socialhierarchical arrangements at hand in each given situation, might consequently exert its effects quite differently in low- vs. high-power situations (Levin \& Sidanius, 1999; Sidanius \& Pratto, 1999; Sidanius et al., 2004). An instantiation 
of such an interaction has been reported by Kemmelmeier (2005), who found that white (high status) participants in a mock-jury showed opposite effects of SDO on punishment contingent on the relative status of the defendant (black or white): High levels of SDO led to more lenient punishment for white defendants, but to harsher punishments in the case of black defendants. One could more generally assert that individual levels of social dominance could play very different roles depending on the power contingencies at hand. In Kemmelmeier's (2005) case, SDO motivated harsher punishment of black (low status) defendants by white (higher status) participants so as to foster the hierarchy-enhancing motives that underpin individual differences in social dominance (e.g., Pratto et al., 1994). But in other cases, different interactions between SDO and grouplevel variables may materialize. According to social dominance theory (e.g., Sidanius \& Pratto, 1999), and specifically its so-called "asymmetry hypothesis," the effects of SDO become stronger among lower status or low-power groups. Individuals with high levels of social dominance who nonetheless belong to lowpower groups may fail to show the typical in-group favoritism in judging a deviant peer and would rather judge the in-group deviant more harshly as a means to redress a perceived menace to a hierarchy-enhancing arrangement (Sidanius et al., 2004). Following such a framework, we anticipate that SDO interacts with level of power; further, the shape of such interaction is consistent with the asymmetry hypothesis of social dominance theory (Sidanius \& Pratto, 1999), with high SDO being more strongly associated with punishment of group members in the low-power group than in the high-power group.

\section{Effects of power on SDO}

We also derived a secondary hypothesis using social dominance theory. This hypothesis anticipates that power moderates the effects of preexperimental SDO on postexperimental SDO. More specifically, we expect those high in SDO and who enjoy a high-power condition to further increase their levels of SDO. This expectation appears consistent with research showing that social categorizations linked with higher power or status increases social dominance preferences (e.g., Guimond, Dambrun, Michinov, \& Duarte, 2003; Levin \& Sidanius, 1999), and that exercising power fosters the expression of power-enhancing attitudes and dispositions (Keltner et al., 2003). We add to this framework that such effects should be particularly strong for individuals already at high levels of SDO. This hypothesis might appear inconsistent with the notion that SDO is a relatively stable disposition considered by some as a personality trait (e.g., Pratto et al., 1994; Snyder \& Cantor, 1998) and, as such, relatively unresponsive to situational factors. However, as mentioned before, social dominance theory explicitly allows for interactions of SDO with situational contingencies (Pratto et al., 1994; Sidanius \& Pratto, 1999) as well as adjustments of SDO levels to changes in the hierarchical arrangements (Levin \& Sidanius, 1999; Sidanius et al., 2004). Consistent with this, 
it has been shown that dominant and powerful positions and contingencies increase SDO levels (Guimond et al., 2003; Levin \& Sidanius, 1999). Thus, we anticipate a fit between preexperimental levels of social dominance, being assigned to a high-power position, and increased postexperimental SDO levels. In other words, associations between preexperimental and postexperimental SDO scores should be stronger for those assigned to a high-power condition.

\section{The current study}

We hypothesized an interaction between a measured disposition (SDO) and a manipulated contingency (low- vs. high-power). These were the independent variables. We anticipated that the interactions would affect preferences for harsher punishment and postexperimental levels of social dominance. These were the dependent variables. Thus, SDO was measured twice, two months before the experimental session (preexperimental SDO, or pre-SDO) and then again immediately after the experiment (postexperimental SDO, or post-SDO). Note that preexperimental SDO was conceived as an independent variable, while postexperimental SDO played the role of dependent variable. In the experimental setting, we first randomly assigned participants to a low-power or a high-power condition, and then presented to participants a description of an ambiguous target, a fictionalized person, that could be perceived as a free-rider. The task was to decide what kind of punishment should be administered to that person.

We expected SDO dispositional effects to be moderated by the power role played by the participants. Situational sensitivity to threats (low-power) and dispositional attention to status threats (high-SDO) should compound each other, leading to stronger SDO effects on punishment in the low-power compared with the high-power condition. As a secondary hypothesis, we also expected that experiencing high power would lead individuals with an already strong orientation to social dominance to further increase their level of SDO. More formally and empirically stated:

H1: Preexperimental SDO would interact with the power condition in affecting punishment preferences; in particular, stronger effects of preexperimental SDO on harsher punishment preferences would be observed in the low-power condition, compared with the high-power condition;

H2: Preexperimental SDO would interact with the power condition in affecting postexperimental SDO; specifically, postexperimental SDO would increase in the high-power condition, but particularly so for participants with high scores in preexperimental SDO.

Hypotheses were tested by means of moderated regression analyses (e.g., Aiken, West, \& Reno, 1991). This method appeared adequate for testing interactions in 
designs where a manipulated independent variable - power - was expected to interact with a measured disposition-SDO (Cohen, Cohen, West, \& Aiken, 2013).

\section{Method}

\section{Participants and procedure}

A total of 120 Italian undergraduates (102 females, 18 males, mean age 24.2, SD 3.77) participated in exchange for course credit. ${ }^{1}$ Individual differences in SDO were first measured online (pre-SDO). The online questionnaire was presented as a study about personality, and, more specifically as a project focusing on the structure of personal preferences and opinions on social relations among different groups and individuals. Eight weeks later, participants came to the laboratory for the experimental session. Participants were told that the purpose of the research was to investigate the effects of cognitive load on decisionmaking. The two-month gap separating measurement of SDO from the experimental session, and the different cover stories, appear suitable to limit demand characteristics and to reduce biases that could artificially inflate the dispositionby-situation interaction we tested. In the laboratory, participants were asked to complete a series of tasks on a computer. After some sociodemographic questions, a message appeared on screen introducing a series of arithmetical calculations to be solved (purportedly to induce cognitive load, as per the cover story). Instructions also specified that after the arithmetical task, participants would be presented with a business case about which they would be asked to make a decision. After the arithmetical task, which lasted about 10 minutes, participants were randomly assigned to the high-power or low-power conditions (see below). A description of an ambiguously deviant member of an organization was then presented (see below). Finally, participants responded to the dependent variables (punishment preferences and postexperimental SDO). They were then thanked and debriefed. All materials and measures were in Italian.

Of the 120 individuals who participated in the online data collection, 107 attended the experimental session eight weeks later. However, 11 participants incorrectly identified their experimental condition (see below); they were therefore dropped from the analyses. In addition, two participants rendered incomplete responses to the postexperimental SDO scale, leaving a final $N$ of 94 (50 in the high-power condition and 44 in the low-power condition). A one-sample chisquare test revealed that the differential attrition across conditions could be attributed to chance $\left(\chi^{2}(1)=0.375, p=.54\right)$. Considering a low-to-moderate effect size for the expected interactions $\left(f^{2}=.08\right)$ (e.g., Faul, Erdelfer, Lang, \& Buchner, 2007) and $\alpha=.05$, power reached .80 for this sample.

Manipulation. Drawing from Pitesa and Thau (2013), the participants were told that they would be presented with a description of an employee's behavior 
("Mr. Rossi") and that a decision should be taken on how the firm should react to the employee's actions. In the high-power condition, the participants were told that they would be the final decision-makers, having final say on the matter. Participants in the high-power condition could either pick one of the punishment options available or provide a choice of his/her own; in all cases, the participant's choice would be the final decision on the issue. In contrast, in the lowpower condition, participants were told that they would be consulted on the course of action to be taken on the employee's behavior, but that they would not be the effective decision-makers: their preference would be contemplated by the decision-makers but would not necessarily be implemented. Such low-power and high-power conditions conform to the definition of power as a capacity to modify others' states by providing or withholding resources or administering punishment (Keltner et al., 2003). Participants in the high-power condition would therefore display a higher capacity to administer punishments, while participants in the low-power condition would have relatively lower capacity to administer punishments.

Target description. The following description of Mr. Rossi was presented:

Mr. Rossi is a relatively junior employee but nonetheless one of the best performing, always over-performing the firm's targets and often doubling the sales of the average colleague. Recently, Mr. Rossi has reduced his days at work, showing up at the office 2-4 days a week. Some colleagues are irritated by this. Some also complain that Mr. Rossi's market zone is more profitable than theirs; hence, Mr. Rossi manages to outperform the targets while putting in fewer hours. No solid proof for these allegations has been provided. Mr. Rossi retorts that the hours at the office do not matter, targets matter. Notwithstanding this, some colleagues have asked for Mr. Rossi to be punished because - they declare-Mr. Rossi works another job in the time he is absent from the office.

This description was deliberately ambiguous: Mr. Rossi had not violated any formal norm. Presenting a patent breach in normative behavior would reduce the variance in the preferences for punishment. A clear breach of a formal group-norm would make most participants feel norm-bound to express the need for a punitive option, because breaching formal group-norms would elicit a prescriptive focus that would override any possible effect due to individual differences (Marques, Abrams, Paez, \& Taboada, 1998; Pinto, Marques, Levine, \& Abrams, 2010). Therefore, ambiguity of the scenario is crucial to make room for effects that originate from assuming a role (the manipulation) or from individual differences in traits, attitudes, and dispositions. Such ambiguous descriptions of free-riding behaviors have been used before in research on norm violation in intra-group and intergroup contexts (e.g., Baumert \& Schmitt, 2009; Granot, Balcetis, Schneider, \& Tyler, 2014). 


\section{Measures}

Manipulation check. The definition of power we rely on (see Keltner et al., 2003) implied that power brings about perceptions of agency, responsibility for decisions, and the notion that one's decisions are effective and influence the state of affairs as intended. Consequently, we used as manipulation check ratings (7-point scales) of how much the participants felt their role was "active," "responsible," and "crucial," in bringing about the decision. The composite score proved reliable $(\alpha=.79)$. We expected higher scores in this composite in the high-power condition compared with the low-power condition.

We also checked whether the participants had correctly understood the role assigned to them (the manipulation) by clicking on one of two options ("I am the effective decision-maker on the matter of Mr. Rossi" or "I would be consulted in the matter of Mr. Rossi, but I am not the effective decision-maker") that were displayed after the power manipulation was presented.

Social dominance orientation. We measured SDO with the validated Italian version (Aiello, Chirumbolo, Leone, \& Pratto, 2005) of Pratto et al.'s (1994) 16-item scale. This Italian validation of SDO has been shown to be reliable and valid and has been used in several publications (e.g., Leone, Desimoni, \& Chirumbolo, 2014; Leone, Livi, \& Chirumbolo, 2016). SDO was administered at the pretest (pre-SDO; $\alpha=.87$ ) and, as mentioned above, at the end of the experimental session two months later (post-SDO; $\alpha=.86$ ). Test-retest reliability in this sample was satisfactory (.75).

Preference for harsh punishment. The following five punitive options varying in their degree of harshness were presented: (1) "no punishment whatsoever," (2) "no punishment but an informal suggestion to spend more time at the firm," (3) "suspend Rossi for a short period," (4) "withhold Rossi's bonuses," and (5) "fire Rossi." Five-point disagree-agree ratings were collected. The items were averaged by reversing the scores for the lenient options (items 1 and 2). Therefore, higher scores indicated preference for harsher forms of punishment. Reliability was satisfactory $(\alpha=.78)$.

\section{Results}

As a check of the efficacy of the manipulation, we found that, as expected, participants in the high-power condition felt more active, responsible, and crucial in the aggregate summarizing these ratings $(M=3.63, \mathrm{SE}=.11)$ than participants $(M=3.31, \mathrm{SE}=.11)$ in the low-power condition $(t(92)=2.01, p=.048$, $95 \%$ C.I. for the difference $[.001, .63])$. Admittedly though, the effect detected on the manipulation check was weak.

Table 1 reports intercorrelations among variables. The table also summarizes descriptive statistics for males and females. Preference for harsher punishment 
Table I. Correlations among variables and descriptive statistics $(N=94)$.

\begin{tabular}{|c|c|c|c|c|}
\hline & $\begin{array}{l}\text { Preferences } \\
\text { for harsh } \\
\text { punishment }\end{array}$ & $\begin{array}{l}\text { Preexperimental } \\
\text { SDO }\end{array}$ & $\begin{array}{c}\text { Power } \\
\text { manipulation }\end{array}$ & $\begin{array}{c}\text { Postexperimental } \\
\text { SDO }\end{array}$ \\
\hline $\begin{array}{l}\text { Preferences for harsh } \\
\text { punishment }\end{array}$ & I & & & \\
\hline Preexperimental SDO & .14 & I & & \\
\hline Power manipulation & -.14 & .00 & I & \\
\hline Postexperimental SDO & .08 & $.75^{* *}$ & .06 & I \\
\hline Females $M(S D)$ & $2.54(.84)$ & $2.43(.91)$ & - & $2.39(.88)$ \\
\hline Males $M(S D)$ & $2.98(.87)$ & $3.09(.92)$ & - & $2.82(.66)$ \\
\hline Total $M(S D)$ & $2.59(.85)$ & $2.51(.93)$ & - & $2.44(.86)$ \\
\hline
\end{tabular}

Note. SDO: Social Dominance Orientation; Power manipulation: coded 0 for low power and I for high power.

$* * p<.05$.

was not significantly correlated with the manipulated power condition, nor with pre- or post-SDO scores. Both SDO scores were unrelated to the manipulated power condition. In particular, the association between pre-SDO and the manipulated power condition was virtually zero, attesting the effectiveness of the random assignment to conditions in rendering equal pre-SDO levels across groups. Unsurprisingly, pre- and post-SDO scores were tightly correlated.

To test hypotheses H1, we regressed the preferences for harsher punishment on pre-SDO scores, the power manipulation (effect-coded: -1 for lowpower; +1 for high-power), and their interaction (e.g., Aiken et al., 1991; Cohen et al., 2013). All variables were standardized. The main effect for the manipulation was in the direction of stronger preferences for harsh punishment in the low-power condition, yet the coefficient was small and well above the conventional significance threshold $(b=-.14, \mathrm{SE}=.10, p=.17)$. A positive but small and nonsignificant coefficient was also found for the main effect of pre-SDO on punishment $(b=.13, \mathrm{SE}=.098, p=.19)$. More germane to our hypothesis $\mathrm{H} 1$, the interaction of SDO with the power manipulation was supported $(b=-.22, \mathrm{SE}=.098, p=.027)$. The interactive effect indicated that the associations of SDO were moderated by the levels of the power manipulation. To clarify the shape of the interaction, we performed simple slope analyses (e.g., Cohen et al., 2013). Simple slopes revealed that no effect for pre-SDO could be found in the high-power condition $(b=-.09, \mathrm{SE}=.14, p=.51)$, while increases in pre-SDO translated into stronger preferences for harsher punishment in the low-power condition $(b=.35, \mathrm{SE}=.10, p=.01)$. The pattern of predicted means in punishment across power conditions and levels of SDO (Figure 1) graphically 


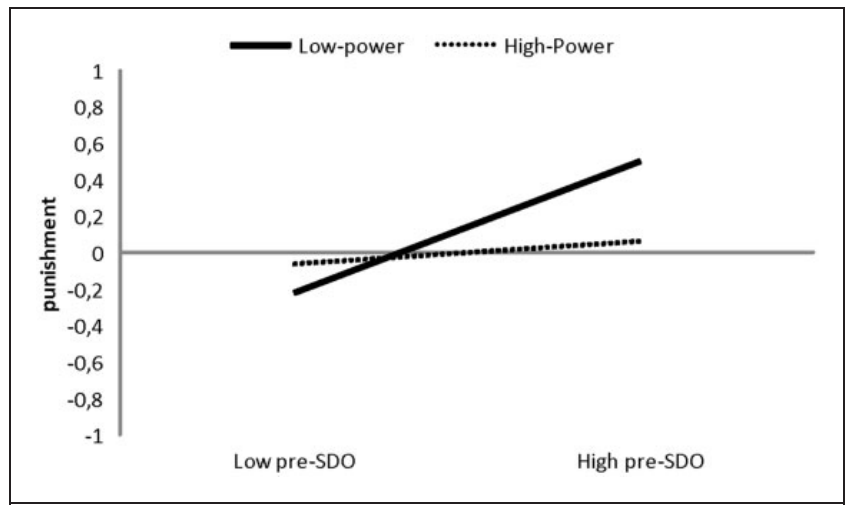

Figure I. Preference for punishment (z-scores) in the two power conditions, at high (I SD above the mean) and low (I SD below the mean) levels of SDO.

conveys the meaning of the interaction: Only in the low-power condition did increases in pre-SDO significantly increase preferences for harsh punishment.

Turning to our second hypothesis (H2), we focused on postexperimental SDO. The hypothesis anticipated that individuals high in preexperimental SDO would further increase their postexperimental SDO levels, but particularly so in the high-power condition. We, therefore, regressed standardized postexperimental SDO scores (the dependent variable) on standardized preexperimental SDO scores, the experimental condition, and their interaction. No effect was observed for the power condition $(b=.04, p=.47)$. Pre-SDO was related with post-SDO across conditions $(b=.75, p<.001)$. More germane to hypothesis $\mathrm{H} 2$, the expected pre-SDO $\times$ power condition interaction materialized $(b=.19$, $p=.007$ ). Simple slopes (Cohen et al., 2013) showed that the effect of preSDO on post-SDO in the high-power condition was significantly stronger $(b=.95, \mathrm{p}<.001)$ than in the low-power condition $(b=.58, p<.001)$. Figure 2 displays the predicted means for $\pm 1 S D$ around pre-SDO levels in the two conditions, showing that increases in postexperimental SDO levels due to variations in preexperimental SDO were steeper in the high-power condition, compared with the low-power condition.

\section{Discussion}

We expected - and found - stronger dispositional effects of SDO on punishment in a low-power condition. We also expected - and found-that being in a highpower contingency would increase the association between preexperimental and postexperimental SDO scores. To put it differently, the high-power contingency moved up postexperimental SDO scores only for those with high levels of preexperimental SDO. The first finding revealed that being in a relatively low-power 




Figure 2. Postexperimental SDO (z-scores) in the two power conditions, at high (I SD above the mean) and low (I SD below the mean) levels of preexperimental SDO.

contingency did not prevent translating personal preferences for dominance into coercive practices. Instead, situational low power facilitated the unleashing of personal dominance on increased preferences for punishment. The second finding supported the claim that power could buttress the individual's dominance disposition. With some latitude, one might infer from this result that power exerts a corruptive influence (Keltner et al., 2003), but only for those sensitive to dominance and status.

\section{The revenge of the weak}

The results are important for understanding the interplay of situational constraints and individual differences in choosing punishment. The dispositional effects of SDO on punishment became strong only when compounded with a relatively low-power status. This is consistent with SDO triggering a motivated resort to punishment to deal with threats to the status quo (e.g., Pratto et al., 1994) and with the idea that SDO motivates retaliation against perceived competitors (Cohrs \& Asbrock, 2009), particularly so among those more vulnerable to competition (i.e., low-power individuals). If some latitude for speculation might be allowed, this might contribute to the current success of populist political movements and leaders in harnessing antiminority attitudes among constituencies selfdescribing as disempowered. This may reflect the enhanced sense of threat that those depicted as free-riders, cheaters, or "deviants" elicit among those who feel left behind. Such forms of backlash against deviants would become stronger for individuals who also hold hierarchy-enhancing attitudes as social dominance and authoritarianism. In effect, it appears that a plurality of supporters of populist movements and candidates hold such attitudes and socio-ideological postures (Choma \& Hanoch, 2017; Eiermann, 2016; Oliver \& Rahn, 2016). 


\section{The dominance of the powerful}

The results also revealed a somewhat nastier side of power, among individuals with already high levels of dispositional social dominance. For participants endorsing an SDO, we observed a stronger increase in postexperimental social dominance levels in the high-power condition. This result suggests that experiencing power encourages the fine-tuning of one's disposition to one's status (e.g., Levin \& Sidanius, 1999). Apparently, noblesse oblige (Fiddick et al., 2013) effects are as important for the noblesse part-enjoying hierarchical status breeds dominance (Guimond et al., 2003) - as they are for the oblige part - the dominant is expected to show chivalrous magnanimity (Fiddick \& Cummins, 2007). The stronger consistency in pre- and postexperimental SDO found could have operated through the greater freedom of dispositional expression associated with power, as those in power are more disinhibited and less likely to rely on situational constraints or social desirability concerns (Keltner et al., 2003). This supports attitude consistency, as seems to be reflected in the stronger test-retest SDO stability found in the high-power condition.

Following social dominance theory (Pratto et al., 1994), this effect should stem from a motive to legitimize the power status through the adoption of consistent dispositional postures (Pratto et al., 1994). This motive appeared stronger among those already embracing high levels of SDO. A somewhat different, though not incompatible, explanation stresses that those in high-power positions adopt higher levels of SDO, as this allows these individuals to express a wider array of hierarchical-enhancing attitudes against lower status groups (Guimond et al., 2003). This reasoning may be interpreted as consistent with the notion that power - eventually - corrupts (Keltner et al., 2003) by increasing hierarchy-enhancing attitudes (Levin \& Sidanius, 1999). We only found this effect of power for those already high in SDO before the experimental manipulations. This adds to the latter argument the proviso that not everyone is similarly sensitive to the corruptive influence of power: Those already subscribing to a hierarchical view on intergroup relations are more so inclined.

\section{Limitations and conclusions}

The following limitations should briefly be mentioned: (a) the limited sample size and (b) the possibility that our results are contingent on our unique methodology, measures, and materials. Specifically, the effect detected on the manipulation check was weak, and a more direct question on power-related perceptions ("How powerful did you feel?") may have revealed a stronger effect.

The sample was gender imbalanced. Although gender effects did not alter our results, a more balanced sample would enhance generalizability. Also, our target (Mr. Rossi) was portrayed as male. Although "Mr. Rossi" is idiomatically used in Italian to refer to a generic individual (with no emphasis on gender), 
counterbalancing the gender's target might have revealed interactions with participants' gender. Of course, other dispositional measures or manipulations of power and status (Cheng, Weidman, \& Tracy, 2014) may reveal different results. We would welcome research showing that different manipulations and measures reveal different patterns of interactions between SDO and power.

Notwithstanding these limitations, our design had also some strengths. For instance, we measured preexperimental SDO and the dependent variables in purportedly unrelated circumstances, two months apart, and this should limit the risks of shared method variance and other demand biases. We also predicted two interactions with opposite signs (on punitivity, and on postexperimental $\mathrm{SDO}$ ), which is a pattern of findings difficult to ascribe to the demand characteristics of the experimental setting or to other spurious influences. It may be noted that the two opposite interaction patterns nonetheless conform nicely with the tenets of social dominance theory (Sidanius \& Pratto, 1999). Altogether then, the results emphasize the flexibility of the social dominance construct. It can function as a means to express stable preferences for social and interpersonal choices (e.g., Sidanius et al., 2004; Snyder \& Cantor, 1998), and it also can serve as a malleable individual difference posture capable of adapting to shifting social circumstances, while maintaining a consistent hierarchy-enhancing motivational drive (Guimond et al., 2003; Levin \& Sidanius, 1999; Sidanius \& Pratto, 1999).

\section{Authors' Note}

Maria Sophia Heering is currently affiliated to school of psychology, University of Kent, UK.

\section{Declaration of Conflicting Interests}

The author(s) declared no potential conflicts of interest with respect to the research, authorship, and/or publication of this article.

\section{Funding}

The author(s) received no financial support for the research, authorship, and/or publication of this article.

\section{Note}

1. The gender distribution was imbalanced. Controlling for gender did not alter the results.

\section{References}

Aiello, A., Chirumbolo, A., Leone, L., \& Pratto, F. (2005). Uno studio di adattamento e validazione della Scala di orientamento/tendenza alia dominanza sociale (Validation of the Italian version of Social Dominance Orientation scale). Rassegna di Psicologia, $22,65-81$. 
Aiken, L. S., West, S. G., \& Reno, R. R. (1991). Multiple regression: Testing and interpreting interactions. Newbury Park, CA: Sage.

Balliet, D., Mulder, L. B., \& Van Lange, P. A. M. (2011). Reward, punishment, and cooperation: A metaanalysis. Psychological Bulletin, 137, 594-614.

Baumert, A., \& Schmitt, M. (2009). Justice-sensitive interpretations of ambiguous situations. Australian Journal of Psychology, 61, 6-12.

Capps, J. S. (2002). Explaining punitiveness: Right-wing authoritarianism and social dominance. North American Journal of Psychology, 4, 263-278.

Carlsmith, K., \& Darley, J. M. (2008). Psychological aspects of retributive justice. In M. P. Zanna (Ed.), Advances in experimental social psychology (Vol. 40, pp. 193-236). San Diego, CA: Elsevier.

Carlsmith, K. M., Darley, J. M., \& Robinson, P. H. (2002). Why do we punish? Deterrence and just deserts as motives for punishment. Journal of Personality and Social Psychology, 83, 284-299.

Carlsmith, K. M., \& Sood, A. M. (2009). The fine line between interrogation and retribution. Journal of Experimental Social Psychology, 45, 191-196.

Cheng, J., Weidman, A., \& Tracy, J. (2014). The assessment of social status: A review of measures and experimental manipulations. In J. Cheng, J. Tracy \& C. Anderson (Eds.), The psychology of social status. New York, NY: Springer.

Choma, B. L., \& Hanoch, Y. (2017). Cognitive ability and authoritarianism: Understanding support for Trump and Clinton. Personality and Individual Differences, 106, 287-291.

Cohen, J., Cohen, P., West, S. G., \& Aiken, L. S. (2013). Applied multiple regression/ correlation analysis for the behavioral sciences. New York, NY: Routledge.

Cohrs, J. C., \& Asbrock, F. (2009). Right-wing authoritarianism, social dominance orientation and prejudice against threatening and competitive ethnic groups. European Journal of Social Psychology, 39, 270-289.

Eiermann, M. (2016). How Donald Trump fits into the history of American populism. New Perspectives Quarterly, 33, 29-34.

Faul, F., Erdelfer, E., Lang, A. G., \& Buchner, A. (2007). G*Power 3: A flexible statistical power analysis program for the social, behavioral, and biomedical sciences. Behavior Research Methods, 39, 175-191.

Fiddick, L., \& Cummins, D. (2007). Are perceptions of fairness relationship-specific? The case of noblesse oblige. Quarterly Journal of Experimental Psychology, 60, 16-31.

Fiddick, L., Cummins, D. D., Janicki, M., Lee, S., \& Erlich, N. (2013). A cross-cultural study of noblesse oblige in economic decision-making. Human Nature, 24, 318-335.

Gollwitzer, M., \& Keller, L. (2010). What you did matters only if you are one of us: Offender's group membership moderates the effect of criminal history on punishment severity. Social Psychology, 41, 20-26.

Gollwitzer, M., \& Van Prooijen, J. W. (2016). Psychology of justice. In S. Clara \& S. Manfred (Eds.), Handbook of social justice theory and research (pp. 61-82). New York, NY: Springer.

Granot, Y., Balcetis, E., Schneider, K. E., \& Tyler, T. R. (2014). Justice is not blind: Visual attention exaggerates effects of group identification on legal punishment. Journal of Experimental Psychology: General, 143, 2196-2208.

Gross, S. R., \& Mauro, R. (1989). Death \& discrimination: Racial disparities in capital sentencing. Boston, MA: Northeastern University Press. 
Guimond, S., Dambrun, M., Michinov, N., \& Duarte, S. (2003). Does social dominance generate prejudice? Integrating individual and contextual determinants of intergroup cognitions. Journal of Personality and Social Psychology, 84, 697-710.

Keltner, D., Gruenfeld, D. H., \& Anderson, C. (2003). Power, approach, and inhibition. Psychological Review, 110, 265-284.

Kafashan, S., Sparks, A., Griskevicius, V., \& Barclay, P. (2014). Prosocial behavior and social status. In J. Cheng, J. Tracy \& C. Anderson (Eds.), The psychology of social status. New York, NY: Springer.

Kemmelmeier, M. (2005). The effects of race and social dominance orientation in simulated juror decision making. Journal of Applied Social Psychology, 35, 1030-1045.

Leone, L., Desimoni, M., \& Chirumbolo, A. (2014). Interest and expertise moderate the relationship between right-wing attitudes, ideological self-placement and voting. European Journal of Personality, 28, 2-13.

Leone, L., Livi, S., \& Chirumbolo, A. (2016). Political involvement moderates the impact of worldviews and values on SDO and RWA. European Journal of Social Psychology, $46,418-427$.

Levin, S., \& Sidanius, J. (1999). Social dominance and social identity in the United States and Israel: Ingroup favoritism or outgroup derogation? Political Psychology, 20, 99-126.

Levin, S., Sidanius, J., Rabinowitz, J. L., \& Federico, C. (1998). Ethnic identity, legitimizing ideologies, and social status: A matter of ideological asymmetry. Political Psychology, 19, 373-404.

Marques, J. M., Abrams, D., Paez, D., \& Taboada, C. (1998). The role of categorization and ingroup norms in judgments of groups and their members. Journal of Personality and Social Psychology, 75, 976-988.

Mazzella, R., \& Feingold, A. (1994). The effects of physical attractiveness, race, SES, and gender of defendant and victims on judgments of mock jurors: A meta-analysis. Journal of Applied Social Psychology, 24, 1315-1344.

Okimoto, T. G., \& Wenzel, M. (2008). The symbolic meaning of transgressions: Towards a unifying framework of justice restoration. In K. A. Hegtvedt \& J. Clay-Warner (Eds.), Advances in group processes: Justice (Vol. 25, pp. 291-326). Bingley, England: Emerald.

Oliver, J. E., \& Rahn, W. M. (2016). Rise of the Trumpenvolk: Populism in the 2016 Election. The ANNALS of the American Academy of Political and Social Science, 667, 189-206.

Pinto, I. R., Marques, J. M., Levine, J. M., \& Abrams, D. (2010). Membership status and subjective group dynamics: Who triggers the black sheep effect? Journal of Personality and Social Psychology, 99, 107-119.

Pitesa, M., \& Thau, S. (2013). Masters of the universe: How power and accountability influence self-serving decisions under moral hazard. Journal of Applied Psychology, 98, 550-558.

Podsakoff, P. M., Bommer, W. H., Podsakoff, N. P., \& MacKenzie, S. B. (2006). Relationships between leader reward and punishment behavior and subordinate attitudes, perceptions, and behaviors: A meta-analytic review of existing and new research. Organizational Behavior and Human Decision Processes, 99, 113-142.

Pratto, F., Sidanius, J., Stallworth, L. M., \& Malle, B. F. (1994). Social dominance orientation: A personality variable predicting social and political attitudes. Journal of Personality and Social Psychology, 67, 741-758. 
Scheepers, D., \& Ellemers, N. (2005). When the pressure is up: The assessment of social identity threat in low and high status groups. Journal of Experimental Social Psychology, 41, 192-200.

Scheepers, D., Branscombe, N. R., Spears, R., \& Doosje, B. (2002). The emergence and effects of deviants in low and high status groups. Journal of Experimental Social Psychology, 38, 611-617.

Sidanius, J., \& Pratto, F. (1999). Social dominance: An intergroup theory of social hierarchy and oppression. New York, NY: Cambridge University Press.

Sidanius, J., Liu, J. H., Shaw, J. S., \& Pratto, F. (1994). Social dominance orientation, hierarchy attenuators and hierarchy enhancers: Social dominance theory and the criminal justice system. Journal of Applied Social Psychology, 24, 338-366.

Sidanius, J., Pratto, F., Van Laar, C., \& Levin, S. (2004). Social dominance theory: Its agenda and method. Political Psychology, 25, 845-880.

Snyder, M., \& Cantor, N. (1998). Understanding personality and social behavior: A functional analysis. In D. T. Gilbert, S. T. Fiske \& G. Lindzey (Eds.), The handbook of social psychology (4th ed., pp. 635-679). Boston, MA: McGraw-Hill.

Van Prooijen, J.-W. (2006). Retributive reactions to suspected offenders: The importance of social categorizations and guilt probability. Personality and Social Psychology Bulletin, 32, 715-726.

Van Prooijen, J. W., \& Lam, J. (2007). Retributive justice and social categorizations: The perceived fairness of punishment depends on intergroup status. European Journal of Social Psychology, 37, 1244-1255.

Wenzel, M., \& Okimoto, T. G. (2016). Retributive justice. In S. Clara \& S. Manfred (Eds.), Handbook of social justice theory and research (pp. 237-256). New York, NY: Springer.

\section{Author Biographies}

Maria Sophia Heering is currently a PhD student at the University of Kent School of Psychology. She graduated in marketing and communication psychology at "Sapienza" University of Rome, Italy. She defended a dissertation titled "Effects of Social Dominance Orientation and role power fit on Evaluation and Motivation." She is currently involved in a cross-disciplinary $\mathrm{PhD}$ research Programme in social psychology and politics. Her current research focuses on "social banditry", more specifically on systematically and empirically analyzing why people support and legitimize 'social bandits', actors, such as gangs, criminal organizations and hackers.

Luigi Leone, $\mathrm{PhD}$, is a professor of psychometrics at the Department of Social and Developmental Psychology, "Sapienza" University of Rome, Italy. His research is focused on individual differences in personality, social and political attitudes. In this line, he published a number of articles on the relations between attitudes and behavior, self-regulation of emotions, motivation, personality structure, right wing political attitudes, political psychology. 